
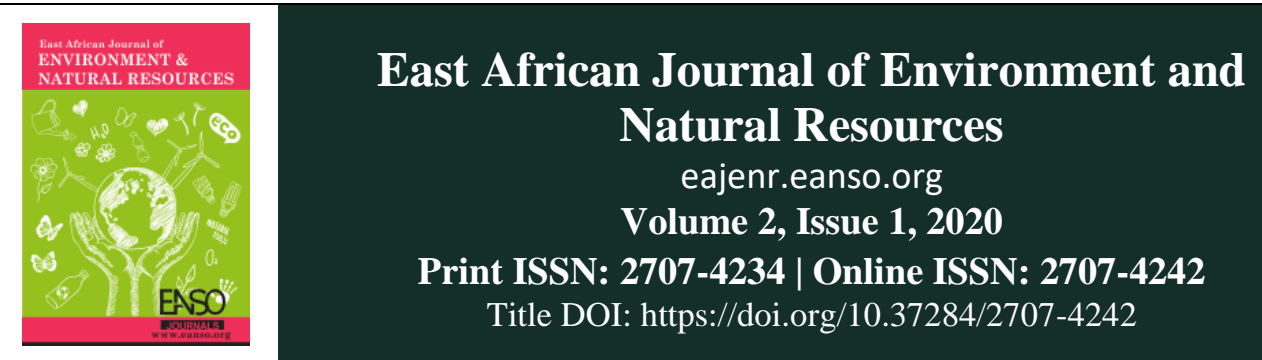

Original Article

\title{
Survey of Flora Affected by Mistletoe Species and Identification of Chlorophyll Pigments in Sokoto State University, Sokoto, Nigeria
}

\author{
Musa Tanko Muhammad ${ }^{*}$, Jabo Abdullahi Dalhatu ${ }^{1}$, Adamu Abdullahi ${ }^{1}$, \\ Murtala Sani Yakubu ${ }^{2}$, \& Ibrahim Ibafidon Madinat ${ }^{3}$, \\ ${ }^{1}$ Department of Biological Sciences, Sokoto State University, Sokoto, Nigeria. \\ ${ }^{2}$ Department of Science Laboratory Technology, Umaru Ali Shinkafi Polytechnic, Sokoto, Nigeria. \\ ${ }^{3}$ Department of Biology, Federal College of Education (Technical) Gusau, Zamfara State, Nigeria. \\ *Author for Correspondence email: muhammad.musatanko@ssu.edu.ng
}

Article DOI: https://doi.org/10.37284/eajenr.2.1.132

Article history:

Received: 24 Feb 2019

Accepted: 16 Mar 2019

Published: 13 Apr 2020

Keywords:

Mistletoe,

Chlorophyll,

Flora,

Azadirachta indica,

Psidium guajava,

Acacia nilotica,

Carotene,

Sokoto,

Nigeria.

\begin{abstract}
A survey was conducted to assess the flora affected by mistletoe species and the identification of chlorophyll pigments in Sokoto State University. This study aimed at surveying the flora affected by mistletoe species and identifies their chlorophyll pigments within the Sokoto State University campus. The area of the study was demarcated into three sampling sites, in accordance of the species studied and their infestation on trees by mistletoes. The species of mistletoe, Tapinanthus globiferus, was common to all the three types of trees (Azadirachta indica, Psidium guajava, and Acacia nilotica). A. nilotica had the highest rate of infestation by mistletoe ( $T$. globiferus) with the percentage of $85.7 \%$ in area A, $91.7 \%$ in area B, and $82.3 \%$ in area C. The estimation of pigment content of chlorophyll in mistletoe leaves showed that all the mistletoe found on the three different types of trees had the same pigment content of chlorophyll-a, chlorophyll-b, and carotene.
\end{abstract}

\section{APA CITATION}

Muhammad, M., Dalhatu, J., Abdullahi, A., Yakubu, M., \& Madinat, I. (2020). Survey of Flora Affected by Mistletoe Species and Identification of Chlorophyll Pigments in Sokoto State University, Sokoto, Nigeria. East African Journal of Environment and Natural Resources, 2(1), 24-30. https://doi.org/10.37284/eajenr.2.1.132.

\section{CHICAGO CITATION}

Muhammad, Musa, Jabo Dalhatu, Adamu Abdullahi, Murtala Yakubu, and Ibrahim Madinat. 2020. "Survey of Flora Affected by Mistletoe Species and Identification of Chlorophyll Pigments in Sokoto State University, Sokoto, Nigeria". East African Journal of Environment and Natural Resources 2 (1), 24-30. https://doi.org/10.37284/eajenr.2.1.132. 


\section{HARVARD CITATION}

Muhammad, M., Dalhatu, J., Abdullahi, A., Yakubu, M. and Madinat, I. (2020) "Survey of Flora Affected by Mistletoe Species and Identification of Chlorophyll Pigments in Sokoto State University, Sokoto, Nigeria", East African Journal of Environment and Natural Resources, 2(1), pp. 24-30. doi: 10.37284/eajenr.2.1.132.

\section{IEEE CITATION}

M. Muhammad, J. Dalhatu, A. Abdullahi, M. Yakubu, and I. Madinat, "Survey of Flora Affected by Mistletoe Species and Identification of Chlorophyll Pigments in Sokoto State University, Sokoto, Nigeria", EAJENR, vol. 2, no. 1, pp. 24-30, Apr. 2020.

\section{MLA CITATION}

Muhammad, Musa, Jabo Dalhatu, Adamu Abdullahi, Murtala Yakubu, and Ibrahim Madinat. "Survey of Flora Affected by Mistletoe Species and Identification of Chlorophyll Pigments in Sokoto State University, Sokoto, Nigeria". East African Journal of Environment and Natural Resources, Vol. 2, no. 1, Apr. 2020, pp. 24-30, doi:10.37284/eajenr.2.1.132.

\section{INTRODUCTION}

The common name of most obligate hemiparasitic is Mistletoe, a plant which the order Santalales. They use haustorium for attachment to their host tree or shrub, which they use to extract water and other nutrients from their host tree. Their parasitic lifestyle has led to some dramatic changes in their metabolism (Mathiasen, Nickrent, Shaw \&Watson, 2002). The name mistletoe originally refers to a species Viscum album (European mistletoe, in the family of the order Santalales); it was the only species native to the British Isles and much of Europe. A separate species, Viscum cruciatum, occurs in Southwest Spain and Southern Portugal, as well in Morocco (North Africa), Southern Africa, and Western Africa (Nigeria) (Der \&Nickrent, 2008).

Mistletoe consists of around 1400 species all over the world and it belongs to the subclass Rosidae, and order Santales (Judd, Campbell, Kellogg, Stevens \& Donaghue, 1999). Recent phylogenetic research indicates mistletoes belong to five distinct families: Misodendronaceae, Eremolepidaceae, Santalaceae, Viscaceae, and Loranthaceae (Der \& Nickrent, 2008). The biggest family is Loranthaceae, with 75 genera and up to 900 species (Judd et al., 1999), with six major genera found in Nigeria: Tapinanthus, Agelanthus, Loranthus, Globimetula, and Phragmanthera. Tapinanthus is more widely spread in Nigerian savannah (Omolaja \& Gamaye, 1998). In some part of Nigeria, it is called Afomo in Yoruba, Apari in Igbo it is Kauci in Hausa, and Children's matches' probably because of the match shaped like structure of the flower. Mistletoe can grow widely on a variety of trees; they inhibit growth and can cause damage to them to some extent with a large scale infestation (Oluwole, Osungunna \& Abimbola, 2013).

Mistletoes are mainly hemiparasitic in nature, their leaves are always green that can photosynthesize; depending on its host as a source of water and other minerals they require. Their seeds can be spread by Aves (Birds) which consume the fruits. Mistletoe seeds can grow attached to their host plant (tree or shrub) and in its early stage of growth, it does not depend on its host. In its later stage, it uses its haustorium for penetrating the tissue of the host for water and other nutrients intake from their host plant (Milius, 2000).

Physiology researches on mistletoe help in understanding the physiological relationship between the parasite (mistletoe) and its host. The studies also allow the researcher to know more about mistletoe, such as its clinical significance, as it noted to a good herbal medicine for some infections. For example, mistletoe is used in the treatment of cancer, such as breast cancer and also used in the treatment of Hepatitis, hypertension, etc. Mistletoe is interesting botanically because it is a semi parasite (hemiparasite). As a parasitic plant, it grows on the branches or trunk of a tree and sends out roots that penetrate into the tree and take up nutrients. It is also capable of growing on its own; like other plants, it can produce its own food through the process of photosynthesis. Mistletoe is of different types of species as it is parasitic on various types of trees as its host. There's little or no record of species of mistletoe found on any tree in the area of study. In order to have document and knowledge of species richness and photosynthetic pigments of hemiparasite in the area of study, the study surveyed the flora affected by mistletoe 
species and to identify their chlorophyll pigments in Sokoto State University Campus.

\section{MATERIALS AND METHODS}

\section{Study Area}

This study was conducted in Sokoto State University, Sokoto, within Sokoto State, Nigeria. Sokoto State is located in north-western Nigeria, which falls within the dry Sahel savannah. It also falls between Latitudes: $13.05^{\circ} \mathrm{N}$ to $13.067^{\circ} \mathrm{N}$ and
Longitude $5^{\prime} 14^{\circ} \mathrm{E}$ to $5^{\prime} 233^{\circ} \mathrm{E}$. The highest daytime temperature is generally under $40{ }^{\circ} \mathrm{C}\left(104.0{ }^{\circ} \mathrm{F}\right)$ most time of the year, and the dryness makes the heat bearable. The rainy seasons start from May/June up to September/October. Harmattan is from late October to February, during the 'cold season,' the climate is dominated by the wind blowing Sahara dust over the land. The dust dims the sunlight, thereby lowering temperatures significantly and also leading to the inconvenience of dust everywhere in the houses (Tsoho, 2008).

\section{Figure 1: Map Showing Sokoto State University, Sokoto, Sokoto State}

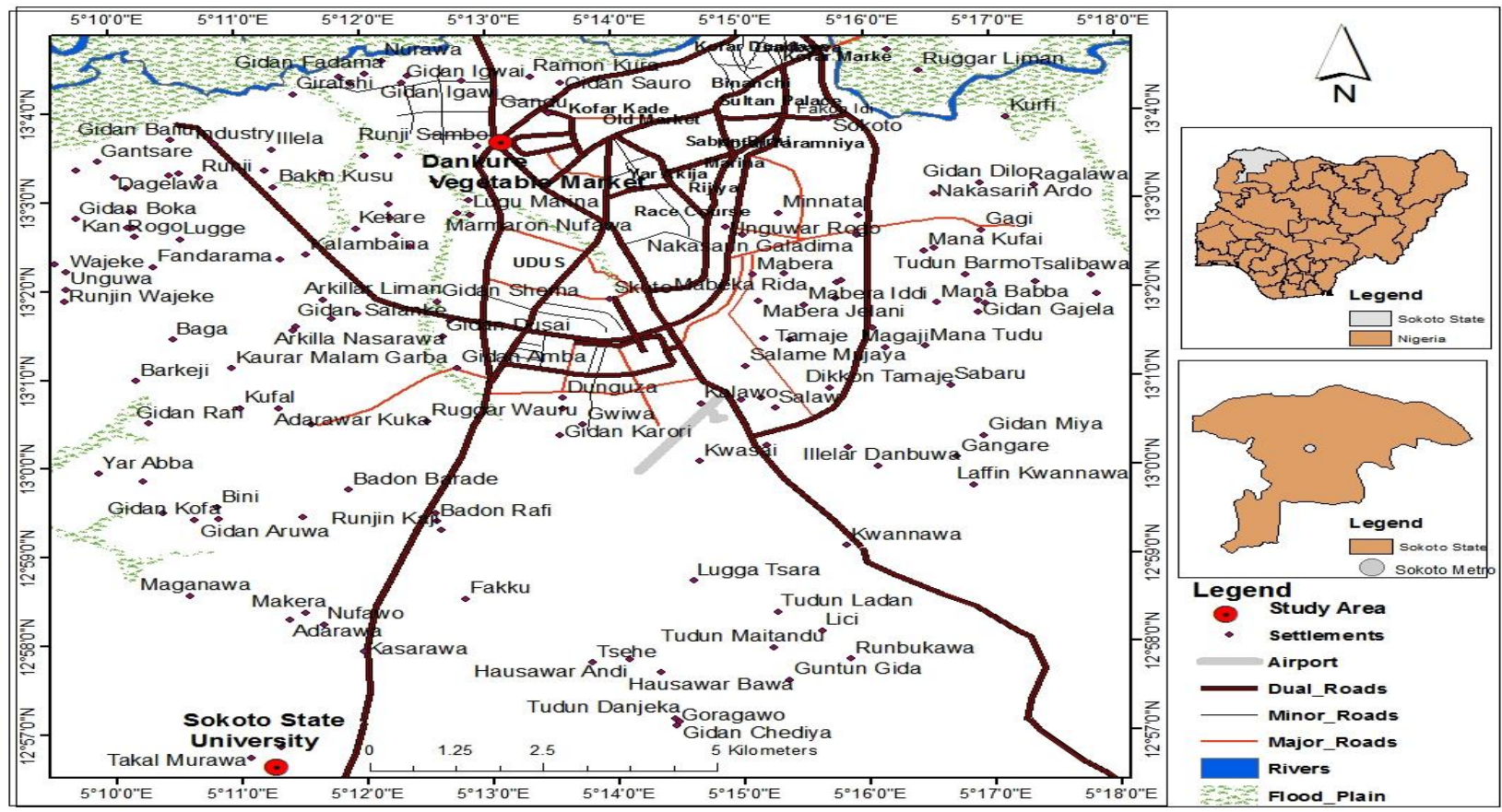

Source: G.I.S Lab. Department of Geography UDUS 2019.

\section{Sample Collection}

Three commonly known species of trees were selected, namely Azadirachta indica, Psidium guajava, and Acacia nilotica for the experiment and Identification purposes. The species selected can grow in both moist and dry conditions under shades in plane land areas. An infected species was collected during the stage of maturity and properly handled during sampling of trees leaves to prevent mechanical injuries.

In each of the sampling areas, the host trees were counted according to their level of infestation by mistletoes and size of the host trees; it was also divided into clusters. The sampling areas A, B, and $\mathrm{C}$ all within Sokoto State University's premises and was divided into 35, 40, and 45 clusters, respectively, making a total of 120 trees, and every cluster was $200 \mathrm{~m}$ of size. The number of Azadirachta indica, Psidium guajava, and Acacia nilotica in every cluster was counted, considering those infected and uninfected by the hemiparasite.

In every sampling site, two separate trees of each of Neem tree (Azadirachta indica), Guava tree (Psidium guajava), and Babul (Acacia nilotica) were selected randomly on the basis of heavy infestation of tree branches by unknown species of mistletoe. Freshly collected leaves of mistletoes 
found on trees were prepared for identification using herbarium techniques. The prepared herbarium was taken for identification to the herbarium of Botany Unit Department of Biological Sciences, Usmanu Danfodio University Sokoto.

\section{Estimation of the Pigment Content of Chlorophyll}

The extract of mistletoe leaves was used for the determination of the chlorophyll pigments. Using a pencil, lines were drawn $1 \mathrm{~cm}$ through the bottom of chromatography paper (a horizontal line), while the other vertical line was drawn through the centre of the paper, which divides the paper into two equal halves down to the horizontal line. A point was made at the margin point of the two lines, which was labelled as (P) and then the chromatography paper was allowed to dry. Using Pasteur pipette, two drops of the mistletoe leaves extract was placed on the paper at that point $P$, which was then allowed to dry. After it was air-dried, a thread was used to tie the paper at the top and it was suspended into the chamber of chromatography containing solvent (mixture of distilled water and isopropyl alcohol), making the pencil line $1 \mathrm{~cm}$ above the solvent level. It was allowed for 8-10 minutes before the different colours begin to separate indicating different chlorophyll pigments. The distance between each colour was measured and the $R_{f}$ value was calculated by the formula below:

$$
R_{f}=\frac{\begin{array}{c}
\text { distance traveled in the component } \\
\text { with the original line }
\end{array}}{\begin{array}{c}
\text { distance traveled in the solvent } \\
\text { with the original line }
\end{array}}
$$

\section{Identification of Mistletoe Species}

At each and every affected plant by mistletoe, the mistletoe on each host plant was collected along with its stem, leaves, and flower. On every mistletoe species that found, it was directly based on its morphological characteristics and suite with book reference of mistletoe identification such as Flora Malesiana Series I-Seed Plants Volume 13 1997 Loranthaceae and Viscaceae; and Flora of Java Volume 2-1965. For species identification in more detail, so the specimen was prepared as herbarium sample which was taken to the Herbarium of Botany unit, Department of Biological Sciences, Usmanu Danfodio University Sokoto for the identification purpose, which was identified by the taxonomists, with the voucher number (UDUH/ANS/0135).

Chi-square $\left(x^{2}\right)$ test was performed for the counting of host type, while the $\mathrm{R}_{\mathrm{f}}$ (Response Factor) was used for data analysis in the extraction of the pigments.

\section{RESULTS AND DISCUSSIONS}

\section{Identification of Mistletoe Species and Prevalence}

The results for the investigation show that the mistletoe affecting different types of trees within Sokoto State University is of the same species. The specie of mistletoes found affecting the host trees was Tapinanthus globiferus (Table 1).

Table 1: Identification of Mistletoe Species on Targeted Host Plants from the Sampling Areas

\begin{tabular}{lllll}
\hline Host plant & \multicolumn{2}{l}{ Identified mistletoe } & Area C & Voucher No. \\
& Area A & Area B & T. globiferus & 0135 \\
\hline A. indica & T globiferus & T. globiferus & T. globiferus & 0135 \\
A. nilotica & T. globiferus & T. globiferus & T. globiferus & 0135 \\
P. guajava & T. globiferus & T. globiferus &
\end{tabular}

The host trees were counted according to the sampled trees and the results obtained indicate that the most affected host tree in the three sampling site was Acacia nilotica (Babul) with the percentage of infection of $85.7 \%$ in area A, $91.7 \%$ in sites B and
$82.3 \%$ in the Area C. Selected host tree species from each of the sampling sites indicating the number of those infected and uninfected by mistletoes (Table 2). 
East African Journal of Environment and Natural Resources, Volume 2, Issue 1, 2020

Article DOI: https://doi.org/10.37284/eajenr.2.1.132

Table 2: Percentage of Infestation of Targeted Trees by Mistletoe

\begin{tabular}{llllllll}
\hline $\begin{array}{l}\text { Sampling } \\
\text { Area }\end{array}$ & Host Trees & $\begin{array}{l}\text { No. of } \\
\text { Trees }\end{array}$ & Infected (\%) & Uninfected (\%) & $\chi^{2}$ & Df & P-values \\
\hline & A. indica & 21 & $7(33.30)$ & $14(66.70)$ & & & \\
& A. nilotica & 14 & $12(85.70)$ & $2(14.30)$ & & 2 & 0.052 \\
A & $P$. guajava & 5 & $2(40.00)$ & $3(60.00)$ & 9.6 & & \\
\hline & A. indica & 20 & $6(30.00)$ & $14(70.00)$ & & \\
& A. nilotica & 12 & $11(91.70)$ & $1(8.30)$ & 11.73 & 2 & 0.052 \\
B & P. guajava & 3 & $1(33.30)$ & $2(66.70)$ & & & \\
\hline & A. indica & 24 & $11(45.80)$ & $13(54.20)$ & & & \\
& A. nilotica & 17 & $14(2.30)$ & $3(17.70)$ & 5.71 & 2 & 0.052 \\
C & P. guajava & 4 & $2(50.00)$ & $2(50.00)$ & & & \\
\hline
\end{tabular}

Table 3: Chlorophyll Pigment Detected in Mistletoe Found Infecting Host Trees

\begin{tabular}{llll}
\hline Host Tree & Pigment & Colour & $\mathbf{R}_{\mathbf{f}}-$ Values \\
\hline \multirow{3}{*}{ Azadirachta indica } & Chlorophyll-a & Blue-green & 0.113 \\
& Chlorophyll-b & Green & 0.170 \\
& Carotene & Orange yellow & 0.545 \\
\hline \multirow{3}{*}{ Acacia nilotica } & Chlorophyll-a & Blue-green & 0.034 \\
& Chlorophyll-b & Green & 0.05 \\
& Carotene & Orange yellow & 0.55 \\
\hline \multirow{2}{*}{ Psidium guajava } & Chlorophyll-a & Blue-green & 0.15 \\
& Carotene & Orange-yellow & 0.20 \\
& Chlorophyll-b & Green & 0.05 \\
\hline
\end{tabular}

Results from these studies clearly show that the extraction of photosynthetic pigments using different solvents may depend on the chemical nature of bioactive molecules (chlorophyll-a, chlorophyll-b, and carotenoids). Research reveals that all the mistletoe from different hosts has similar pigment contents. All the contents of chlorophyll-a, chlorophyll-b, and carotenoids of most for the sampled species, while only in that's of Psidium guajava, the pigment carotenoids were present (Table 3). No significant difference is observed from the trend of pigment extraction as reported earlier from phytoplankton and also from higher plants in the present study. Although slight variations may persist among the experimented plants/species, even among the same extracting solvent, which could be attributed to the inherent physiological characteristics of individual species. Seasonal and Temporal changes and local geological conditions can also be the reason for variations in pigment concentrations in plants; therefore, further study in this context is recommended.

Among the tree species selected in this research, some of them were common in the area. The trees were mainly planted purposely for shade and breaking winds in residential areas of the region. Consequently, the degree of infestation of the trees by mistletoes is high in the study site as affected trees have reduced vegetative growth and fruit yield, or even the tress die if the infestations increase with time. However, if measures are not taken in curtailing this amount of infestations of these trees by mistletoes, especially on Acacia nilotica and Azadirachta indica, the trees will cease to exist.

The plant species in site A was mainly A. nilotica, this was the reason it had the highest percentage of mistletoe species and high level of infestation (which is significantly different with those from other tree species) as the availability of host trees in 
an area may affect the parasitisation of mistletoe as suggested by Norton and Carpenter (1998). These results were in support with Asare-Bediako, et al. (2013) who also suggested that a high level of infection and high severity indices from $20 \%$ and 90\% among Citrus trees in an orchard in Ghana.

Collection of mistletoes from the three sampling sites indicated that the host plant, A. nilotica showed a high infestation $(58.26 \%)$ having the same species of mistletoes, then $A$. indica and $P$. guajava compared with other host plants. This may be attributed to the relative abundance and susceptibility of A. nilotica to mistletoes more than other host plants, host choices with mistletoes may include, the host plant characteristics (like the height of host plant, host branch size, the susceptibility of the host plant to mistletoe attack, etc.) and the feeding patterns of agents of dispersal. Similar suggestions were made by Aukema and Martinez del Rio (2002) and Didier et al. (2009).

Norton and Carpenter (1998) suggested that the relative abundance of citrus and guava from the study site affected the host selection of mistletoe. A similar report by McC (1994) suggested that the characteristics like the size of branches, age of host trees and heights of the host trees may have a big influence on mistletoe attachment, which may result in size-related mistletoe infection patterns. It was noticed that, within the several species of mistletoe obtained from the different host trees, $T$. globiferus and G. braunii were the most common and found parasitizing all the five host trees. This may be why their seeds were being very sticky in nature than other types mistletoe seeds, thus enhances their distribution by Aves (Birds) and other animals (Del Rio, Silva, Medel \& Hourdequin, 1996; Aukema, 2004). It may also be as a result of the fact that there being less hostspecific compared to the other mistletoe species (Boussim, Guinko, Tuquet \& Sallé, 2004). The results also indicate that the entire three tree species used in this study (A. indica, A. nilotica, and $P$. guajava) were affected by the same species of mistletoe (Tapinanthus globiferus).

\section{CONCLUSION AND RECOMMENDATIONS}

The results indicate mistletoes may parasitize different types of tree species, with some of them having special preference flora and certain types of host plant. Factors such as the availability of host plant and vulnerability (host characteristics) of the host plant may affect the parasitization of the plant with mistletoe. In the three studied tree species, $A$. nilotica was the main tree being parasitized and vulnerable to mistletoe infestation in Sokoto State University campus and T. globiferus is the common species of mistletoe on the three host tree species. However, the rate of infestation of A. nilotica in the study site requires the attention of many people in that area for raising many questions on why the species $A$. nilotica being the most affected specie in the university.

On the other hand, the physiological studies of mistletoes show that mistletoes undergo the process of photosynthesis like other plants; therefore, they have the photosynthetic pigments that help in the process of photosynthesis. Being a semi-parasitic plant does not make mistletoe depends completely on its host, but rather provides some of its need through the process of photosynthesis.

Mistletoe as a hemiparasite should be given consideration, to know more about its biology. The medicinal uses of mistletoes are something also that need to be taken into consideration and give more emphasis on due to its importance in humans health, as it can be used to cure cancer; more especially, breast cancer one of the biggest problems that women are facing around the globe. It is also recommended to carry out an investigation on the chemistry of mistletoe to knowledge on the chemical composition of different species of mistletoe on the campus. Research on the method of dispersal of the seeds and its distribution of such a semi-parasitic plant is also recommended. However, further research on mistletoe species richness and the rate of infestation of other tree species within Sokoto State University be encouraged to have knowledge on the presence of other species of mistletoe not identified in this study and the tree species that could be endangered or threatened by mistletoes and to find out more about the photosynthetic content of mistletoe. 


\section{REFERENCES}

Asare-Bediako, E., Addo-Quaye, A. A., Tetteh, J. P., Buah, J. N., Van Der Puije, G. C., \& Acheampong, R. A. (2013). Prevalence of mistletoe on citrus trees in the Abura-AsebuKwamankese District of the Central Region of Ghana. International Journal of Scientific \& Technology Research, 2(7), 122-127.

Aukema, J. E. (2004). Distribution and dispersal of desert mistletoe is scale-dependent, hierarchically nested. Ecography, 27(2), 137144.

Aukema, J. E., \& Martinez del Rio, C. (2002). Mistletoes as parasites and seed-dispersing birds as disease vectors: current understanding, challenges, and opportunities. In Levey, D., Silva W. and Galetti M. (Eds), Seed dispersal and frugivory: ecology, evolution, and conservation (p. 99-110). Wallingford, UK: CABI International.

Boussim, I. J., Guinko, S., Tuquet, C., \&Sallé, G. (2004). Mistletoes of the agroforestry parklands of Burkina Faso. Agroforestry Systems, 60(1), 39-49.

Del Rio, C. M., Silva, A., Medel, R., \&Hourdequin, M. (1996). Seed dispersers as disease vectors: bird transmission of mistletoe seeds to plant hosts. Ecology, 77(3), 912-921.

Der, J. P., \&Nickrent, D. L. (2008). A molecular phylogeny of Santalaceae (Santalales). Systematic Botany, 33(1), 107116.

Didier, D. S., Laurier, E. O. N., Din, N., Jules, P. R., Victor, T., Henri, F. ... \&Akoa, A. (2009). Artificial infestations of Tapinanthusogowensis (Engler) Danser (Loranthaceae) on three host species in the Logbessou Plateau (Douala, Cameroon). African Journal of Biotechnology, 8(6).

Judd, W. S., Campbell, C. S., Kellogg, E. A., Stevens, P. F., \& Donoghue, M. (1999). Plant systematics: A phylogenetic approach. Sunderland, MA, USA: Sinauer Associates Inc.
Mathiasen, R. L., Nickrent, D. L., Shaw, D. C., \& Watson, D. M. (2008). Mistletoes: pathology, systematics, ecology, and management. Plant disease, 92(7), 988-1006.

McC, J. (1994). Dispersal and infection in mistletoe metapopulations. Journal of Ecology, 711-723.

Milius, S. (2000). Botany under the Mistletoe. Science News, 158, 412-5.

Norton, D. A., \& Carpenter, M. A. (1998). Mistletoes as parasites: host specificity and speciation. Trends in Ecology \& Evolution, 13(3), 101-105.

Oluwole, O., Osungunna, M. O., \& Abimbola, Y. (2013). Phytochemical and antimicrobial screening of Globimetulaoreophila (Oliv) van Tiegh and Phragmantheracapitata (Spreng) Balle. International Journal of Green Pharmacy (IJGP), 7(2), 127-130.

Omolaja, S. S., \& Gamaye, A. O. (1998). The incidence of mistletoes on coffee in Ibadan, Nigeria. In A paper presented at the 9th Annual Conference of the Botanical Society of Nigeria. Nigeria: University of Ilorin.

Tsoho, U. H. (2008). Growth and History of the Establishment of MakeraAssada in Sokoto Metropolist to the year 2007. BA Project. History Department, Usmanu Danfodiyo University Sokoto. 